Article

\title{
Evaluation of Colorectal Cancer Incidence Trends in the United States (2000-2014)
}

\author{
Benjamin E. Ansa ${ }^{1, *(1)}$, Steven S. Coughlin ${ }^{2}$, Ernest Alema-Mensah ${ }^{3}$ (D) and Selina A. Smith ${ }^{4}$ \\ 1 Institute of Public and Preventive Health, Augusta University, Augusta, GA 30912, USA \\ 2 Department of Clinical and Digital Health Sciences, College of Allied Health Sciences, Augusta University, \\ Augusta, GA 30912, USA; scoughlin@augusta.edu \\ 3 Department of Community Health and Preventive Medicine, Morehouse School of Medicine, Atlanta, \\ GA 30310, USA; eamensah@msm.edu \\ 4 Department of Family Medicine, Medical College of Georgia, Augusta University, Augusta, GA 30912, USA; \\ sesmith@augusta.edu \\ * Correspondence: bansa@augusta.edu; Tel.: +1-706-721-6141
}

Received: 28 December 2017; Accepted: 23 January 2018; Published: 30 January 2018

\begin{abstract}
Colorectal cancer (CRC) incidence rates have declined in recent years for people of all races/ethnicities; however, the extent to which the decrease varies annually by demographic and disease-related characteristics is largely unknown. This study examines trends and annual percent change (APC) in the incidence among persons diagnosed with CRC in the United States of America from 2000-2014. The data obtained from the National Cancer Institute's Surveillance, Epidemiology, and End Results (SEER) Program were analyzed, and all persons $(N=577,708)$ with malignant CRC recorded in the SEER 18 database from 2000 to 2014 were characterized according to sex, race, age at diagnosis, disease site and stage. Incidence rates and APC were calculated for the entire study period. Overall, the incidence rate of CRC decreased from 54.5 in 2000 to 38.6 per 100,000 in 2014, with APC $=-2.66(p<0.0001)$. Decline in rates was most profound between 2008 and 2011 from 46.0 to 40.7 per 100,000 (APC $=-4.04 ; p<0.0001)$. Rates were higher for males (vs. females; rate ratio $(R R)=1.33$ ) and for blacks (vs. whites; $R R=1.23$ ). Proximal colon cancers at the localized stage were the predominant cancers. An increase in rate was observed among people younger than 50 years $(6.6$ per 100,000, APC $=1.5)$. The annual rate of CRC has decreased over time. However, the development and implementation of interventions that further reduce the disparities among demographic and disease-related subgroups are warranted.
\end{abstract}

Keywords: Colorectal cancer; incidence; rates; annual percent change; SEER

\section{Introduction}

Colorectal cancer (CRC), a major clinical and public health concern, is the third most common cancer diagnosed and the second leading cause of cancer-related deaths for both men and women in the United States of America (US) [1]. According to the American Cancer Society, 135,430 new cases, and 50,260 deaths from CRC are expected to occur in 2017, and the lifetime risk of developing CRC is about 1 in 21 (4.7\%) for men and 1 in 23 (4.4\%) for women [2]. The management of CRC is associated with substantial health care costs, with national expenditures exceeding $\$ 14$ billion annually [3,4].

The risk of CRC can be reduced through lifestyle modifications and screening [2,5]. Lifestyle factors that may reduce the risk of CRC include consuming a diet high in fruits and vegetables; maintaining a healthy body weight, minimizing alcohol intake; abstaining from tobacco use; use of nonsteroidal anti-inflammatory drugs; and greater consumption of calcium, fiber, folate, and vitamin $\mathrm{D}$; and engaging in regular physical activity (colon cancer). Factors associated with an increased risk of CRC include older age, male sex, a family history of colon or rectal cancer, a history of colorectal 
polyps, inflammatory bowel disease, obesity, type 2 diabetes mellitus, and consuming a diet high in red and processed meat $[2,5-7]$.

Since more than $90 \%$ of cases occur in people who are 50 years or older [5], the US Preventive Services Task Force recommends screening for CRC in adults beginning at age 50 years and continuing until age 75 [8]. Screening with both the noninvasive fecal occult blood test and colonoscopy reduce CRC incidence and mortality [8-11]. As a result of screening and improved treatment over the last few decades, there are now, in the US, more than 1 million survivors of CRC [2].

Factors such as race/ethnicity, age, socioeconomic status [12-18], and cancer-related characteristics influence CRC outcomes [19]. Although, in recent years, CRC incidence and mortality rates have declined for men and women of all races/ethnicities [1], the extent to which the decrease varies annually by age, race, gender, site and stage is largely unknown. To better inform future research on CRC, and to guide the planning and implementation of programs for CRC prevention and control, the present study of current data for the CRC population in the US examines trends and annual percent change (APC) in the incidence among persons diagnosed with CRC from 2000-2014.

\section{Materials and Methods}

\subsection{Data Source}

The data were obtained from the National Cancer Institute's Surveillance, Epidemiology, and End Results (SEER) Program, which is a main source for cancer statistics in the US and includes information on incidence, prevalence, and survival from specific geographic areas representing $28 \%$ of the population [20,21]. SEER also compiles reports on cancer mortality for the entire country [20,21]. Data collection began in the early 1970s and gradually expanded. Data for the present analysis were obtained from the 18 SEER registries that are currently operating.

\subsection{Study Population and Measures}

All persons with CRC recorded in the SEER 18 database from 2000 to 2014 were characterized according to sex, race, age at diagnosis, and disease site and stage. Included were cases in the SEER database with malignant behavior and known age; cases of unknown age were excluded. Sex was reported as either male or female; race was classified as white, black, other (American Indian, Alaskan Native, Asian/Pacific Islander), or unknown. Ages were grouped as $<40,40-49,50-59,60-69,70-79$, and $80+$ years.

CRCs were grouped into three major anatomic primary sites: proximal colon, distal colon, and rectum. The International Classification of Diseases for Oncology, third edition (ICD-O-3) was used to select all CRC malignant cases reported to the SEER Program from 2000 through 2014 that originated from the following primary sites (and ICD-O-3 codes): proximal colon (cecum (C18.0), appendix (C18.1), ascending colon (C18.2), hepatic flexure of colon (C18.3), transverse colon (C18.4), splenic flexure of colon (C18.5)); distal colon (descending colon (C18.6), and sigmoid colon (C18.7)); and rectum (recto-sigmoid junction (C19.9), and rectum, not otherwise specified (C20.9)). Overlapping lesion of colon (C18.8), and colon, not otherwise specified (C18.9) were grouped as other.

Stage at diagnosis was categorized according to the SEER historic stage A classification scheme. It categorizes cancer cases as localized, regional, distant, or unstaged based on the following definitions [20,21]: localized cancer is cancer that is limited to the organ in which it began without evidence of spread; regional cancer is cancer that has spread beyond the original (primary) site to nearby lymph nodes or organs and tissues; distant cancer is cancer that has spread from the primary site to distant organs or distant lymph nodes; and unstaged cancer is cancer for which there is not enough information to indicate a stage. 


\subsection{Statistical Analyses}

For the entire study period, incidence rates and trends of CRC were calculated by sex, race, age, stage and site, and were expressed as the number of cases per 100,000 individuals (age-adjusted to the 2000 US Standard Population) accompanied by the $95 \%$ confidence intervals (CIs). SEER ${ }^{*}$ Stat software (version 8.3.4, Surveillance Research Program, National Cancer Institute, Bethesda, MD, USA) [22] was used for analyzing incidence rates, trends, and rate ratios. Rate ratios (RRs) and the corresponding 95\% CIs were calculated, as described by Tiwari et al. [23], to examine the differences in rates between men and women; among whites, black, and individuals of other racial groups; between the age groups; and among the sites and stages.

Changes in incidence rates over time were evaluated and expressed as APC and corresponding CIs and $p$-values. This was calculated by utilizing Joinpoint Regression Program (Version 4.5.0.1, Statistical Methodology and Applications Branch, Surveillance Research Program, National Cancer Institute, Bethesda, MD, USA) [24-26]. The APC indicates the cancer rate change at a constant percentage of the rate of the previous year, and is obtained by fitting a least-squares regression line to the natural logarithm of the rates using the calendar year as a regressor variable (the model is linear on the log of the response for calculating annual percentage rate change) $[21,25,27]$. The incidence data were further analyzed by use of joinpoint models, which were aimed at evaluating longitudinal data for a change in trend. An APC was computed for each of those trends by means of generalized linear models, assuming a Poisson distribution. Changes in trend were tested for statistical significance using a Monte Carlo permutation method [25,26]. All $p$-values for significance testing of APC $=0$ were two-sided, and considered to be of statistical significance when $p<0.05$ [27]. Significant changes included changes in direction or in the rate of increase or decrease.

\section{Results}

\subsection{Demographic and Cancer Characteristics}

Between 2000 and 2014, a total of 577,708 malignant CRC cases were recorded in the 18 SEER registries (Table 1). The majority were male $(51.5 \%, n=297,320)$, predominantly white $(80 \%, n=462,221)$, and older than 50 years $(90 \%, n=519,770)$. Almost $43 \%(n=247,656)$ presented with cancer in the proximal colon that was localized $(41 \%, n=236,262)$. The distributions of patient demographic characteristics and cancer primary sites did not differ significantly over time.

Table 1. Characteristics of colorectal cancer (CRC) cases by year of diagnosis (18 Surveillance, Epidemiology, and End Results (SEER) Program registries, 2000-2014).

\begin{tabular}{|c|c|c|c|c|}
\hline Characteristics & $\begin{array}{c}\text { Total } \\
N=577,708(\%)\end{array}$ & $\begin{array}{c}2000-2004 \\
n=197,716(\%)\end{array}$ & $\begin{array}{c}2005-2009 \\
n=193,012(\%)\end{array}$ & $\begin{array}{c}2010-2014 \\
n=186,980(\%)\end{array}$ \\
\hline \multicolumn{5}{|l|}{ Sex } \\
\hline Male & $297,320(51.5)$ & $100,633(51.0)$ & $99,304(51.4)$ & $97,383(52.1)$ \\
\hline $\begin{array}{l}\text { Female } \\
\text { Race }\end{array}$ & $280,388(48.5)$ & $97,083(49.1)$ & $93,708(48.6)$ & 89,597 (47.9) \\
\hline White & $462,221(80.0)$ & $162,577(82.2)$ & $154,310(79.9)$ & 145,334 (77.7) \\
\hline Black & $66,475(11.5)$ & $21,399(10.8)$ & $22,327(11.6)$ & $22,749(12.2)$ \\
\hline * Other & $44,989(7.8)$ & $12,950(6.6)$ & $15,171(7.9)$ & $16,868(9.0)$ \\
\hline Unknown & $4023(0.7)$ & $790(0.4)$ & $1204(0.6)$ & $2029(1.1)$ \\
\hline \multicolumn{5}{|l|}{ Age } \\
\hline$<40$ & $15,312(2.6)$ & $4631(2.3)$ & $4944(2.6)$ & $5737(3.1)$ \\
\hline $40-49$ & $42,626(7.4)$ & $13,174(6.7)$ & $14,556(7.5)$ & $14,896(8.0)$ \\
\hline $50-59$ & $103,684(18.0)$ & $30,620(15.5)$ & 35,399 (18.3) & $37,665(20.1)$ \\
\hline $60-69$ & $131,512(22.8)$ & $42,519(21.5)$ & $43,316(22.4)$ & $45,677(24.4)$ \\
\hline $70-79$ & $148,149(25.6)$ & $57,591(29.1)$ & $48,458(25.1)$ & $42,100(22.5)$ \\
\hline $80+$ & $136,425(23.6)$ & $49,181(24.9)$ & $46,339(24.0)$ & $40,905(22.0)$ \\
\hline
\end{tabular}


Table 1. Cont.

\begin{tabular}{|c|c|c|c|c|}
\hline Characteristics & $\begin{array}{c}\text { Total } \\
N=577,708(\%)\end{array}$ & $\begin{array}{c}2000-2004 \\
n=197,716(\%)\end{array}$ & $\begin{array}{c}2005-2009 \\
n=193,012(\%)\end{array}$ & $\begin{array}{c}2010-2014 \\
n=186,980(\%)\end{array}$ \\
\hline \multicolumn{5}{|l|}{ Stage } \\
\hline Localized & $236,262(40.9)$ & $80,112(40.5)$ & $80,050(41.5)$ & $76,100(40.7)$ \\
\hline Regional & 192,289 (33.3) & $68,430(34.6)$ & $63,916(33.1)$ & $59,943(32.0)$ \\
\hline Distant & 111,909 (19.4) & $35,994(18.2)$ & $36,878(19.1)$ & 39,037 (20.9) \\
\hline Unstaged & $37,248(6.4)$ & $13,180(6.7)$ & $12,168(6.3)$ & $11,900(6.4)$ \\
\hline \multicolumn{5}{|l|}{ ** Primary site } \\
\hline Proximal colon & $247,656(42.9)$ & $84,430(42.7)$ & $83,209(43.1)$ & 80,017 (42.8) \\
\hline Distal colon & 138,377 (23.9) & $49,673(25.1)$ & 46,207 (23.9) & $42,497(22.7)$ \\
\hline Rectum & $165,932(28.7)$ & $54,840(27.7)$ & $55,177(28.6)$ & 55,915 (29.9) \\
\hline$* * *$ Other & $25,743(4.5)$ & $8,773(4.5)$ & $8,419(4.4)$ & $8,551(4.6)$ \\
\hline
\end{tabular}

Note: SEER-Surveillance, Epidemiology, and End Results; * Other race- American Indian/AK Native, Asian/Pacific Islander; ${ }^{* *}$ Primary site: proximal colon-cecum, appendix, ascending colon, hepatic flexure, transverse colon, splenic flexure; distal colon-descending colon, sigmoid colon; rectum- rectosigmoid junction, rectum not otherwise specified; ** Other site-overlapping lesion of colon, and colon, not otherwise specified.

\subsection{CRC Rates/Trends for each Year from 2000 to 2014}

Figure 1a shows the age-adjusted rates and APC for CRC cases. Overall, the rate of CRC decreased from 54.5 in 2000 to 38.6 per 100,000 in 2014, with APC $=-2.66(p<0.0001)$. Figure $1 \mathrm{~b}$ illustrates two joinpoints for rates and corresponding APCs. Between 2000 and 2008, rates decreased from 54.5 to 46.0 per 100,000 (APC $=-2.20 ; p<0.0001$ ); and, between 2008 and 2011, from 46.0 to 40.7 per 100,000 $(\mathrm{APC}=-4.04 ; p<0.0001)$. Between 2011 and 2014, the decrease from 40.7 to 38.6 per 100,000 was statistically significant (APC $=-1.87 ; p<0.0001)$. The overall crude rates were slightly lower with the overall $\mathrm{APC}=-1.33 ; p<0.0001$ (zero joinpoint). The two joinpoints for the crude rates showed corresponding lower APCs for 2000-2008, 2008-2011 and 2011-2014 (-1.06, -2.41 and -0.17 respectively) (Figure 2a,b).

\subsection{Overall CRC Rates/Trends for the Entire Time Period between 2000 and 2014}

As presented in Table 2, the overall age-adjusted incidence rate of CRC in the US for all individuals and all ages during the study period was 45.9 per $100,000(95 \% \mathrm{CI}=45.8,46.0$ per 100,000), with APC $=-2.7(p<0.0001)$. Although persons who were 60 years and older had higher rates of CRC, the decline in CRC incidence was also greater in this population (APCs between -3.3 and -3.8 per 100,000) compared to persons who were 50-59 years old $($ APCs $=-0.5)$. An increasing trend was observed among persons less than 50 years, with rates at 2.3 per 100,000 (APC $=2.7 ; p<0.0001$ ) for persons $<40$ years, and 22.5 per 100,000 (APC $=1.7 ; p<0.001$ ) for those between 40 and 49 years. The incidence rate was higher for blacks (56.1 compared to 45.6 per 100,000 for whites), but the APC was slightly greater for whites than for blacks ( -2.7 vs. -2.5$)$. Males had a higher incidence rate and greater APC (53.4 per $100,000($ APC $=-2.9 ; p<0.001)$ ) than females (39.9 per 100,000 (APC $=-2.5 ; \mathrm{p}<0.0001)$ ). More people presented with cancers of the proximal colon $(20.0$ per 100,000) that were localized $(18.7$ per 100,000). The greatest declines in CRC rates were among persons 70 years and older (APC $=-3.8 ; p<0.0001$ ) and among those presenting with distal colon cancer (APC $=-3.6 ; p<0.0001)$. The highest APCs for declining rates were in cases of regional spread (APC $=-3.3 ; p<0.0001$ ) and unstaged cancer (APC $=-3.5 ; p<0.0001$ ). The crude rate ratios for the demographic and disease-related variables were only slightly lower from the age-adjusted values (results not shown). 
Age-adjusted rates of colorectal cancer in the US: 2000 to 2014 : All : 0 Joinpoints

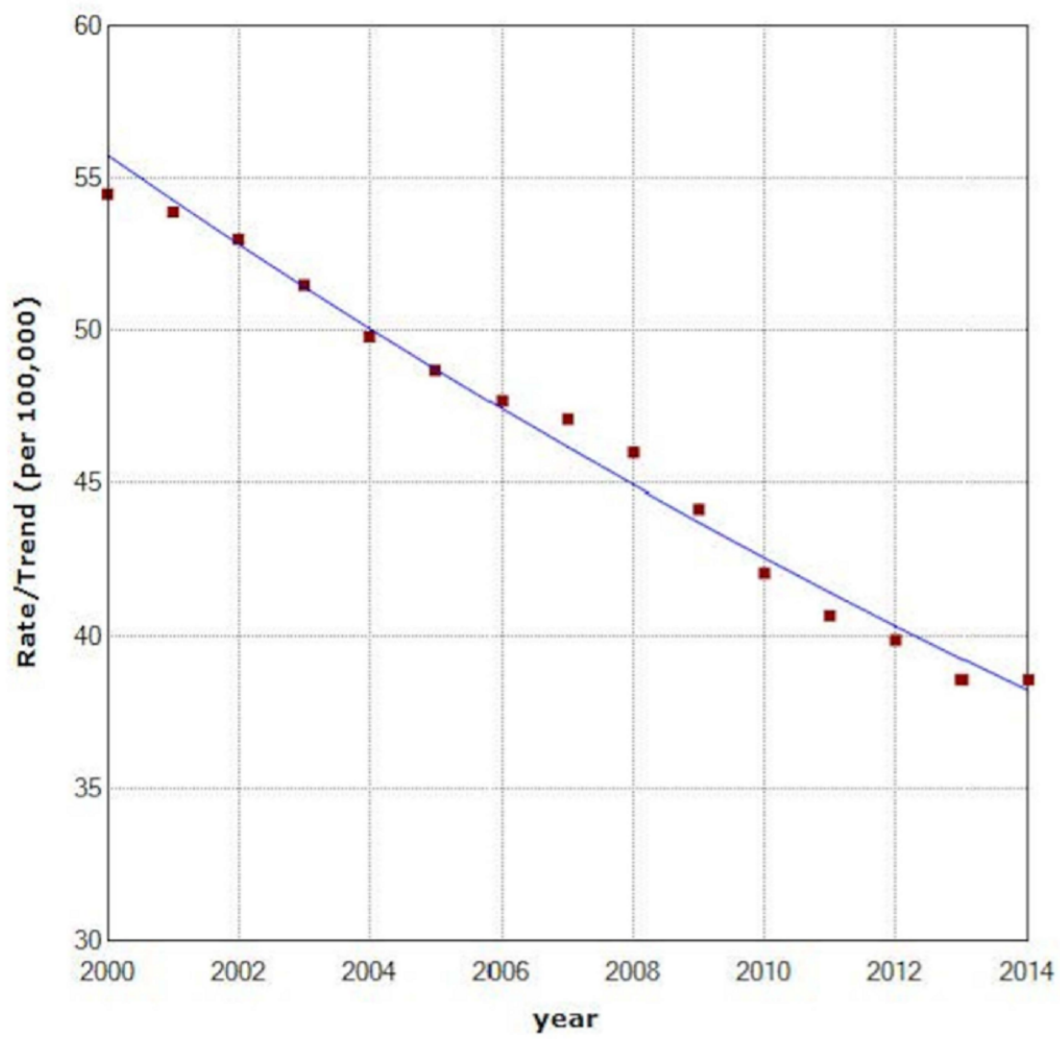

\begin{tabular}{|c|c|c|}
\hline Yeard & Rateq & Std-Errork \\
\hline 2000প & $54.5 x$ & $0.3 \not$ \\
\hline 2001я & $53.9 x$ & 0.36 \\
\hline $2002 x$ & $53.0 x$ & $0.3 x$ \\
\hline 2003a & $51.5 x$ & $0.3 x$ \\
\hline 2004ם & $49.8 x$ & $0.3 x$ \\
\hline 2005a & $48.7 x$ & $0.3 \alpha$ \\
\hline 2006a & $47.7 x$ & $0.2 x$ \\
\hline $2007 x$ & 47.1x & $0.2 x$ \\
\hline 2008da & $46.0 x$ & $0.2 x$ \\
\hline 2009x & $44.2 x$ & $0.2 x$ \\
\hline 2010প & 42.1x & $0.2 x$ \\
\hline 2011প & $40.7 x$ & $0.2 x$ \\
\hline $2012 x$ & $39.9 x$ & $0.2 x$ \\
\hline 2013a & $38.6 x$ & $0.2 x$ \\
\hline 2014x & $38.6 x$ & $0.2 x$ \\
\hline \multicolumn{3}{|c|}{ APC-·Annual.Percentage·Change; $\cdot \wedge p<0.0001 \not$} \\
\hline
\end{tabular}

(a)

Figure 1. Cont. 
Age-adjusted rates of colorectal cancer in the US: 2000 to $2014:$ All : 2 Joinpoints

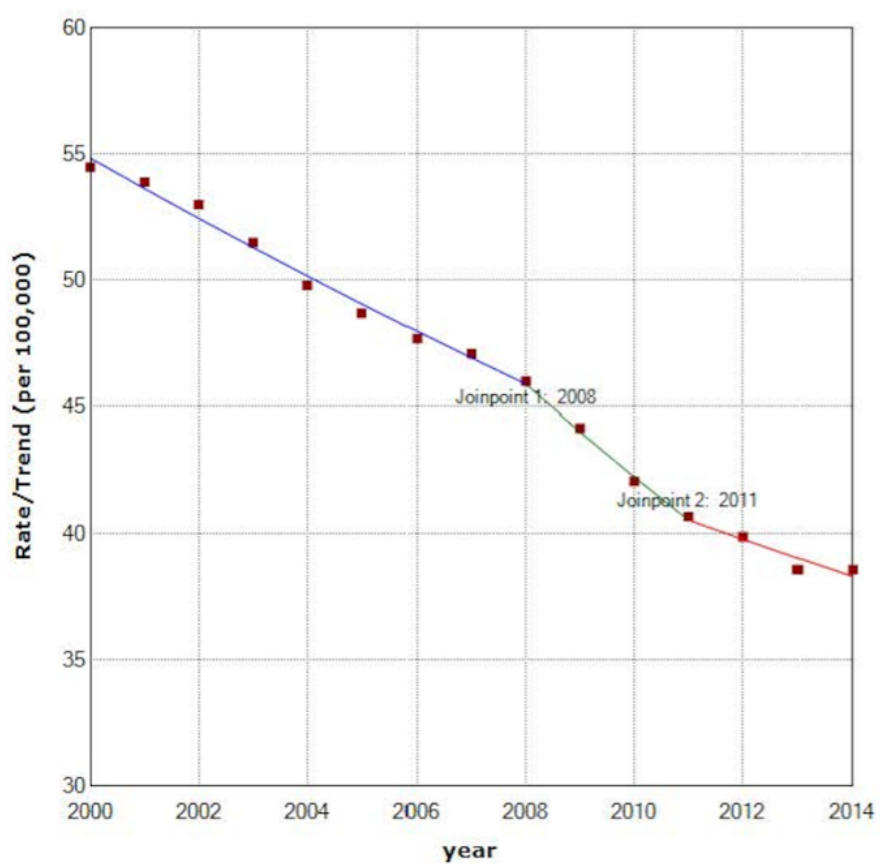

- Observed

-2000-2008 APC $=-2.20^{\circ}$ - 2008-2011 APC $=-4.04^{\wedge}$

\begin{tabular}{|c|c|c|c|}
\hline Year & Rate & Std Error & $\begin{array}{l}\text { Joinpoint } \\
\text { Location }\end{array}$ \\
\hline 2000 & 54.5 & 0.3 & \\
\hline 2001 & 53.9 & 0.3 & \\
\hline 2002 & 53.0 & 0.3 & \\
\hline 2003 & 51.5 & 0.3 & \\
\hline 2004 & 49.8 & 0.3 & \\
\hline 2005 & 48.7 & 0.3 & \\
\hline 2006 & 47.7 & 0.2 & \\
\hline 2007 & 47.1 & 0.2 & \\
\hline 2008 & 46.0 & 0.2 & Joinpoint 1 \\
\hline 2009 & 44.2 & 0.2 & \\
\hline 2010 & 42.1 & 0.2 & \\
\hline 2011 & 40.7 & 0.2 & Joinpoint 2 \\
\hline 2012 & 39.9 & 0.2 & \\
\hline 2013 & 38.6 & 0.2 & \\
\hline 2014 & 38.6 & 0.2 & \\
\hline
\end{tabular}

(b)

Figure 1. (a) Age-adjusted rates of colorectal cancer in USA: 2000-2014: All: 0 Joinpoints. (b) Age-adjusted rates of colorectal cancer in USA: 2000 to 2014: All: 2 Joinpoints. 
Crude rates of colorectal cancer in the US: 2000-2014 : All : 0 Joinpoints

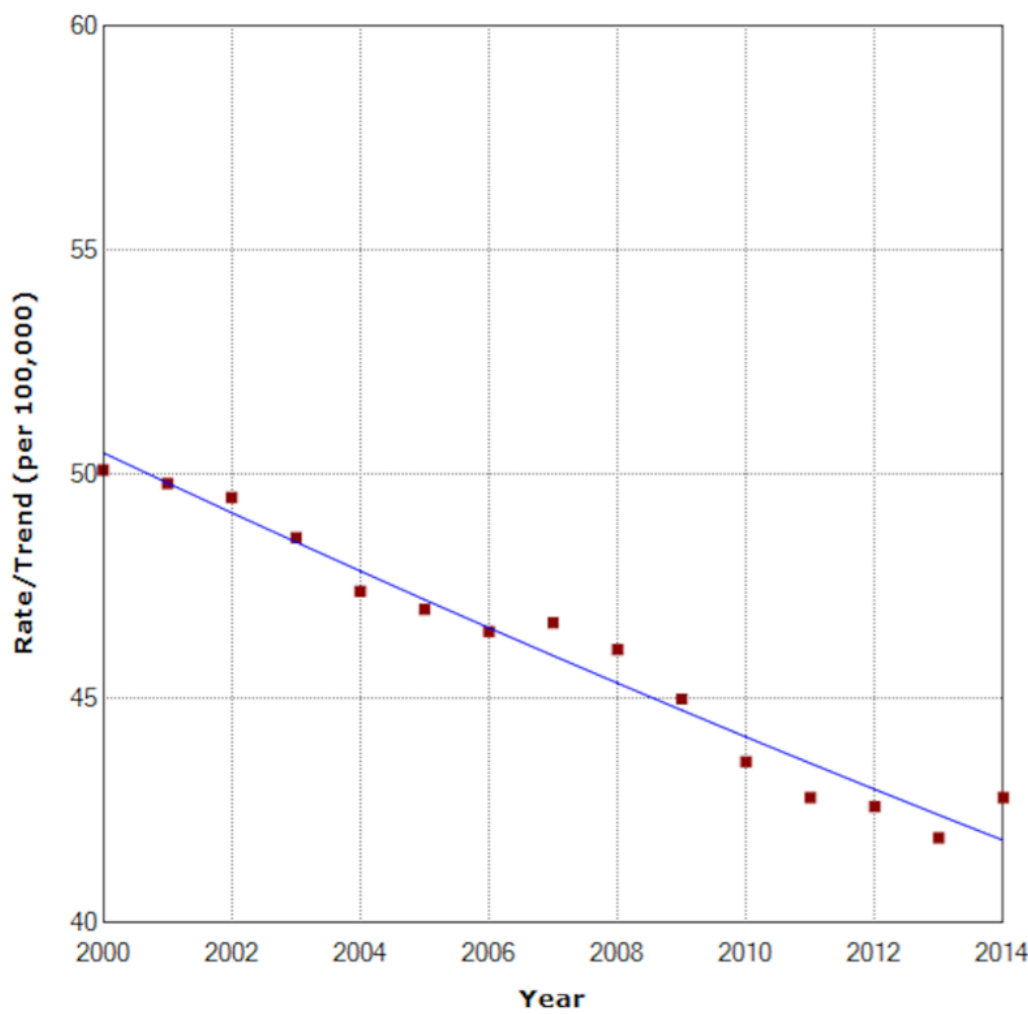

- Observed

- 2000-2014 APC $=-1.33^{\wedge}$

\begin{tabular}{|c|c|c|}
\hline Year & Rate & Std Error \\
\hline 2000 & 50.1 & 0.4 \\
\hline 2001 & 49.8 & 0.4 \\
\hline 2002 & 49.5 & 0.3 \\
\hline 2003 & 48.6 & 0.2 \\
\hline 2004 & 47.4 & 0.2 \\
\hline 2005 & 47.0 & 0.2 \\
\hline 2006 & 46.5 & 0.2 \\
\hline 2007 & 46.7 & 0.2 \\
\hline 2008 & 46.1 & 0.2 \\
\hline 2009 & 45.0 & 0.2 \\
\hline 2010 & 43.6 & 0.2 \\
\hline 2011 & 42.8 & 0.2 \\
\hline 2012 & 42.6 & 0.2 \\
\hline 2013 & 41.9 & 0.2 \\
\hline 2014 & 42.8 & 0.2 \\
\hline APC- Annual Percentage Change; ${ }^{\wedge} p$-value $<0.0001$ \\
\hline \multicolumn{2}{|c|}{} \\
\hline \multicolumn{2}{|c|}{} \\
\hline \multicolumn{2}{|c|}{} &
\end{tabular}

(a)

Figure 2. Cont. 
Crude rates of colorectal cancer in the US: 2000-2014: All : 2 Joinpoints

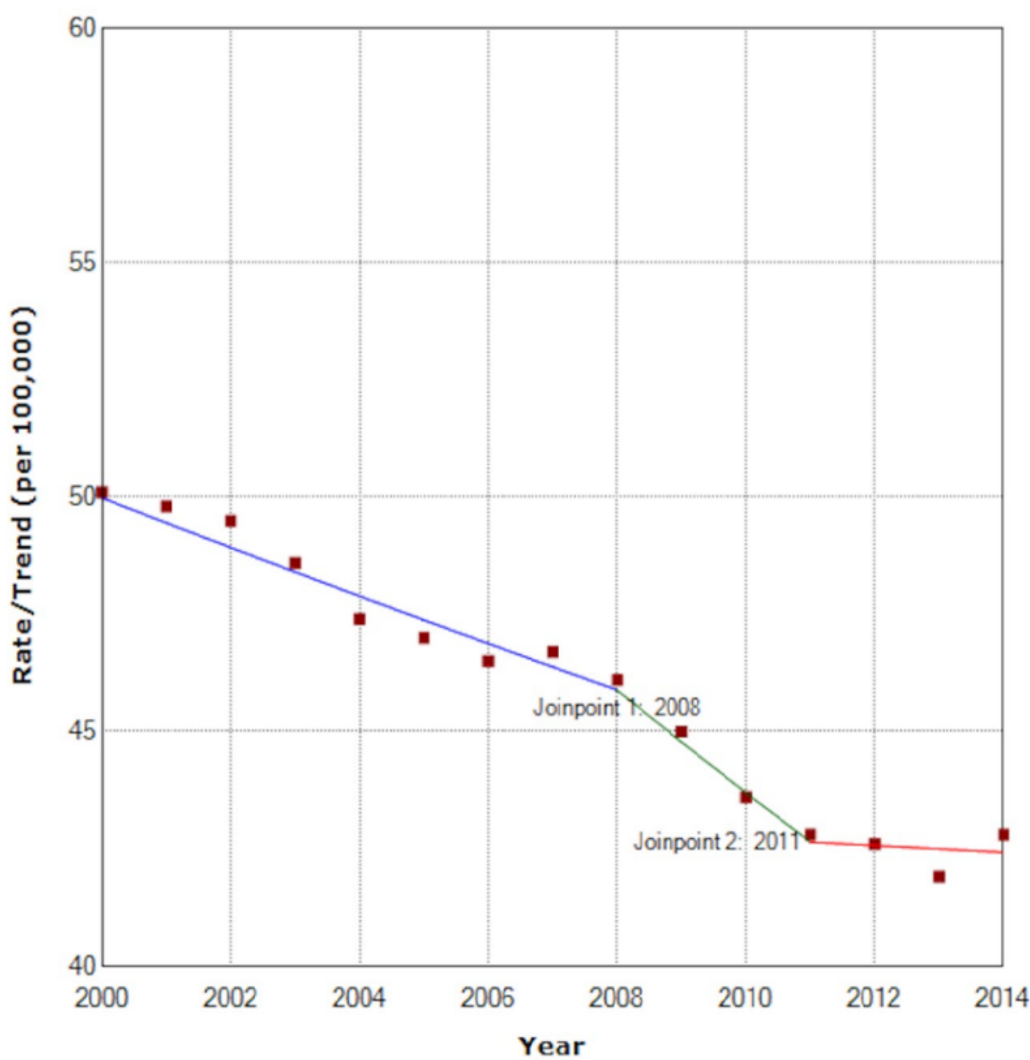

\begin{tabular}{|c|c|c|c|}
\hline Year & Rate & Std Error & $\begin{array}{c}\text { Joinpoint } \\
\text { Location }\end{array}$ \\
\hline 2000 & 50.1 & 0.4 & \\
\hline 2001 & 49.8 & 0.4 & \\
\hline 2002 & 49.5 & 0.3 & \\
\hline 2003 & 48.6 & 0.2 & \\
\hline 2004 & 47.4 & 0.2 & \\
\hline 2005 & 47.0 & 0.2 & \\
\hline 2006 & 46.5 & 0.2 & \\
\hline 2007 & 46.7 & 0.2 & \\
\hline 2008 & 46.1 & 0.2 & Joinpoint 1 \\
\hline 2009 & 45.0 & 0.2 & \\
\hline 2010 & 43.6 & 0.2 & \\
\hline 2011 & 42.8 & 0.2 & Joinpoint 2 \\
\hline 2012 & 42.6 & 0.2 & \\
\hline 2013 & 41.9 & 0.2 & \\
\hline 2014 & 42.8 & 0.2 & \\
\hline APC- Annual Percentage Change; $\wedge p$-value $<0.0001$ & \\
\hline \multicolumn{5}{|c|}{}
\end{tabular}

(b)

Figure 2. (a) Crude rates of colorectal cancer in the USA: 2000-2014: All: 0 Joinpoints. (b) Crude rates of colorectal cancer in the USA: 2000-2014: All: 2 Joinpoints. 
Table 2. Age-adjusted rates of CRC in the US, (18 Surveillance, Epidemiology, and End Results (SEER) Program registries, 2000-2014).

\begin{tabular}{|c|c|c|c|c|c|c|c|c|c|}
\hline \multirow{2}{*}{$\begin{array}{c}\begin{array}{c}\text { Population } \\
\text { Groups }\end{array} \\
\text { All groups }\end{array}$} & \multirow{2}{*}{$\begin{array}{l}\text { Rate } \\
45.9\end{array}$} & \multirow{2}{*}{$\begin{array}{c}\begin{array}{c}\text { Standard } \\
\text { Error }\end{array} \\
0.1\end{array}$} & \multicolumn{2}{|c|}{$\begin{array}{l}\text { 95\% C.I (Rate) } \\
\text { Lower/Upper }\end{array}$} & \multirow[t]{2}{*}{$\begin{array}{l}\text { Rate } \\
\text { Ratio }\end{array}$} & \multicolumn{2}{|c|}{$\begin{array}{l}\text { 95\% C.I (Rate Ratio) } \\
\text { Lower/Upper }\end{array}$} & \multirow{2}{*}{$\begin{array}{l}\text { APC } \\
-2.7\end{array}$} & \multirow{2}{*}{$\begin{array}{c}p \text {-Value } \\
\text { (APC) }\end{array}$} \\
\hline & & & 45.8 & 46.0 & & & & & \\
\hline Male & 53.4 & 0.1 & 53.2 & 53.6 & Ref. & & & -2.9 & $<0.001$ \\
\hline $\begin{array}{c}\text { Female } \\
\text { Race }\end{array}$ & 39.9 & 0.1 & 39.8 & 40.1 & 0.75 & 0.74 & 0.75 & -2.5 & $<0.001$ \\
\hline White & 45.6 & 0.1 & 45.5 & 45.7 & Ref. & & & -2.7 & $<0.001$ \\
\hline Black & 56.1 & 0.2 & 55.6 & 56.5 & 1.23 & 1.22 & 1.24 & -2.5 & $<0.001$ \\
\hline * Other & 37.5 & 0.2 & 37.2 & 37.9 & 0.82 & 0.81 & 0.83 & -2.3 & $<0.001$ \\
\hline \multicolumn{10}{|l|}{ Age (Years) } \\
\hline$<40$ & 2.3 & 0.0 & 2.3 & 2.4 & Ref. & & & 2.7 & $<0.001$ \\
\hline $40-49$ & 22.5 & 0.2 & 22.1 & 22.8 & 9.72 & 9.41 & 10.03 & 1.7 & $<0.001$ \\
\hline $50-59$ & 64.1 & 0.2 & 63.7 & 64.5 & 27.27 & 9.67 & 9.87 & -0.5 & $<0.001$ \\
\hline $60-69$ & 128.6 & 0.4 & 127.9 & 129.3 & 53.55 & 19.41 & 19.80 & -3.3 & $<0.001$ \\
\hline $70-79$ & 232.2 & 0.6 & 231.0 & 233.4 & 100.45 & 35.07 & 35.75 & -3.8 & $<0.001$ \\
\hline $\begin{array}{c}80+ \\
\text { Stage }\end{array}$ & 329.8 & 0.9 & 328.1 & 331.6 & 142.98 & 49.81 & 50.79 & -3.8 & $<0.001$ \\
\hline Localized & 18.7 & 0.0 & 18.7 & 18.8 & Ref. & & & -2.6 & $<0.001$ \\
\hline Regional & 15.4 & 0.0 & 15.3 & 15.4 & 0.82 & 0.82 & 0.83 & -3.3 & $<0.001$ \\
\hline Distant & 8.9 & 0.0 & 8.8 & 8.9 & 0.47 & 0.47 & 0.48 & -1.3 & $<0.001$ \\
\hline Unstaged & 2.9 & 0.0 & 2.9 & 3.0 & 0.16 & 0.15 & 0.16 & -3.5 & $<0.001$ \\
\hline \multicolumn{10}{|l|}{ ** Primary site } \\
\hline Proximal colon & 20.0 & 0.0 & 19.9 & 20.1 & Ref. & & & -2.5 & $<0.001$ \\
\hline Distal colon & 10.9 & 0.0 & 10.9 & 11.0 & 0.55 & 0.54 & 0.55 & -3.6 & $<0.001$ \\
\hline Rectum & 13.0 & 0.0 & 12.9 & 13.0 & 0.65 & 0.64 & 0.65 & -2.0 & $<0.001$ \\
\hline$* * *$ Other & 2.1 & 0.0 & 2.0 & 2.1 & 0.10 & 0.10 & 0.10 & -2.5 & $<0.001$ \\
\hline
\end{tabular}

Note: SEER-Surveillance, Epidemiology, and End Results; rates are per 100,000 and age-adjusted to the 2000 US standard population (19 age groups-Census P25-1130); C.I- confidence intervals (Tiwari model) are 95\% for rates and ratios; APC is significantly different from zero if $p<0.05, *$ Other race- American Indian/AK Native, Asian/Pacific Islander, ** Primary site: proximal colon- cecum, appendix, ascending colon, hepatic flexure, transverse colon, splenic flexure; distal colon- descending colon, sigmoid colon; rectum- rectosigmoid junction, rectum not otherwise specified; ${ }^{* *}$ Other site- overlapping lesion of colon, and colon, not otherwise specified.

\section{Discussion}

This study provides important information about the incidence and trends of CRC in the US. The study population consisted of slightly more males, was mostly whites, and was 50 years and older. The overall incidence rate for CRC between 2000 and 2014 was 45.9 per 100,000 and APC $=-2.7$. Rates were higher for males (vs. females; $R R=1.33$ ) and for the blacks (vs. whites; $R R=1.23$ ). Proximal colon cancers at the localized stage were the predominant cancers. The greatest decrease in rates was for cancers in the distal colon, at localized stage, and among persons older than 70 years. There was an increase in rate among people younger than 50 years (6.6 per 100,000, APC $=1.5$ ).

The current results are similar to those reported by previous studies that analyzed temporal trends in CRC incidence [28-32]. Siegel et al. [28], analyzed the SEER 9 data for 2009 through 2013, and reported an overall incidence rate for CRC of 40.7 per 100,000 persons. There was a $32 \%$ decline in the rate among people 50 years and older and an accelerated rate of decline, from 298.3 (per 100,000) in 2000 to 186.8 in 2013, for people 65 years and older. From 2000 to 2013, CRC incidence rates increased by $22 \%$ among individuals younger than 50 years. Incidence rates were higher for men than for women and were higher for blacks than for whites and other racial groups $[29,31,32]$. The most common tumor location was the proximal colon $(42 \%)$, followed by the rectum $(28 \%)[28,30]$.

Increased uptake of screening, which rose from 38\% in 2000 to $59 \%$ in 2013 for adults aged 50 years or older, may explain the declines in CRC incidence among age groups older than 55 years [33-35]. Differences in the uptake of screening may also account for differences in the incidence trends for individuals aged 50 years and older. The receipt of a colonoscopy in the past 10 years increased dramatically from $14 \%$ in 2000 to $41 \%$ in 2013 among individuals of ages 50 to 54 years, from $16 \%$ to $52 \%$ in those of ages 55 to 59 years, and from $25 \%$ to $63 \%$ in those of ages 65 years and older [33]. 
Lifestyle behaviors, such as consuming unhealthy diets and physical inactivity, with the resultant increase in the prevalence of overweight and obesity are possible factors contributing to the increased rates of CRC among people younger than 50 years [34]. CRC in younger patients tends to be more aggressive and more advanced at presentation than late-onset CRC [16,36,37]. Adults younger than 50 years without risk factors are not recommended to undergo routine screening for CRC, and this may also be a potential explanation for the rising incidence trends, and advanced cancer presentation in this population $[18,27]$. The data from this study revealed an APC in the incidence of CRC of 2.7 and 1.7 for individuals $<40$ and $40-49$ years respectively. These results are similar to those from Siegel et al [34] revealing that adults ages 20 to 39, had colon cancer incidence rates increase by $1 \%$ to $2 \%$ per year; and adults 40 to 54 , with rates increase by $0.5 \%$ to $1 \%$ per year from the mid-1990s through 2013. Also, Bailey et al (2015) reported a $1.99 \%$ increase in the rates of CRC among 20-34 year old, and $0.41 \%$ increase among 35-49 year old individuals from 1975-2010. These data give credence for the need to review the current guidelines for CRC screening to begin at earlier ages than those currently recommended.

The sharp decline observed in the overall rates (APC of -4.40) from 2008 through 2011 (Figure 1b) is likely due in part to increased uptake of routine CRC screening. CRC screening uptake in the US may have received a boost after being promoted at the nation's first colon cancer awareness month in March of 2000 and public health campaigns such as Screen for Life [38-40]. The high rate of proximal colon cancer compared to the other subsites may be due to the use of flexible sigmoidoscopy with inspection of the rectum and distal colon. More evidence-based studies may further explain the higher rate of proximal colon cancer.

The strength of this study includes the large sample size which enables SEER-based studies to have sufficient power for detecting relatively moderate associations and permits a variety of multivariable analyses [21,41]. The population- based, as opposed to institution-based, identification of patients increases the generalizability of findings. Although institutional studies often gather more detailed information about each patient, those studies usually are confined to major referral centers and may not be representative of the patients with CRC who are treated in community hospitals and clinics. The main limitation of this study pertains to the lack of data on demographic variables, such as health insurance coverage, education, marital, and income status. SEER 18 registries contain data representing only $28 \%$ of the U.S.A. population that are not randomly selected; therefore, selection and confounding biases are possible limitations [42].

\section{Conclusions}

The annual rate of CRC has decreased over time, especially among individuals older than 70 years; however, not all population subgroups are benefitting from this trend. The development and implementation of interventions that further reduce the disparities in CRC incidence among demographic and disease-related subgroups are warranted.

Acknowledgments: This work was supported by the National Cancer Institute [R01CA166785].

Author Contributions: Benjamin E. Ansa conceived and designed the study; Benjamin E. Ansa analyzed the data; all the authors contributed in writing and editing the manuscript.

Conflicts of Interest: The authors declare no conflict of interest. The funding sponsors had no role in the design of the study; in the collection, analyses, or interpretation of data; in the writing of the manuscript, and in the decision to publish the results.

\section{References}

1. United States Cancer Statistics Working Group. 1999-2013 Incidence and Mortality Web-Based Report. Available online: http:/ / www.cdc.gov / uscs (accessed on 8 May 2017).

2. American Cancer Society. Colorectal Cancer Facts E Figures 2017-2019; American Cancer Society: Atlanta, GA, USA, 2017; Available online: https:/ / www.cancer.org/content/dam/cancer-org/research/cancer-facts-and-statistics/ colorectal-cancer-facts-and-figures / colorectal-cancer-facts-and-figures-2017-2019.pdf (accessed on 8 May 2017). 
3. Mariotto, A.B.; Yabroff, K.R.; Shao, Y.; Feuer, E.J.; Brown, M.L. Projections of the cost of cancer care in the United States: 2010-2020. J. Natl. Cancer Inst. 2011, 103, 117-128. [CrossRef] [PubMed]

4. May, F.P.; Glenn, B.A.; Crespi, C.M.; Ponce, N.; Spiegel, B.M.R.; Bastani, R. Decreasing Black-White Disparities in Colorectal Cancer Incidence and Stage at Presentation in the United States. Cancer Epidemiol. Biomark. Prev. 2017, 26, 762-768. [CrossRef] [PubMed]

5. Division of Cancer Prevention and Control, Centers for Disease Control and Prevention 2016. Available online: https:/ / www.cdc.gov/cancer/colorectal/basic_info/risk_factors.htm (accessed on 8 May 2017).

6. World Cancer Research Fund and American Institute for Cancer Research Food. Food, Nutrition, Physical Activity, and the Prevention of Cancer: A Global Perspective; American Institute for Cancer Research: Washington, DC, USA, 2007.

7. Giovannucci, E.; Wu, W. Cancers of the colon and rectum. In Cancer Epidemiology and Prevention, 3rd ed.; Schottenfeld, D., Fraumeni, J.F., Jr., Eds.; Oxford University Press: New York, NY, USA, 2006; pp. 809-829.

8. US Preventive Services Task Force; Bibbins-Domingo, K.; Grossman, D.C.; Curry, S.J.; Davidson, K.W.; Epling, J.W., Jr.; Garcia, F.A.R.; Gillman, M.W.; Harper, D.M.; Kemper, A.R.; et al. Screening for colorectal cancer: us preventive services task force recommendation statement. JAMA 2016, 315, 2564-2575. [PubMed]

9. Mandel, J.S.; Church, T.R.; Bond, J.H.; Ederer, F.; Geisser, M.S.; Mongin, S.J.; Snover, D.C.; Schuman, L.M. The effect of fecal occult-blood screening on the incidence of colorectal cancer. N. Engl. J. Med. 2000, 343, 1603-1607. [CrossRef] [PubMed]

10. Shaukat, A.; Mongin, S.J.; Geisser, M.S.; Lederle, F.A.; Bond, J.H.; Mandel, J.S.; Church, T.R. Long-term mortality after screening for colorectal cancer. N. Engl. J. Med. 2013, 369, 1106-1114. [CrossRef] [PubMed]

11. Nishihara, R.; Wu, K.N.; Lochhead, P.; Morikawa, T.; Liao, X.Y.; Qian, Z.R.; Inamura, K.; Kim, S.A.; Kuchiba, A.; Yamauchi, M.; et al. Long-term colorectal-cancer incidence and mortality after lower endoscopy. N. Engl. J. Med. 2013, 369, 1095-1105. [CrossRef] [PubMed]

12. Doubeni, C.A.; Laiyemo, A.O.; Klabunde, C.N.; Young, A.C.; Field, T.S.; Fletcher, R.H. Racial and Ethnic trends of colorectal cancer screening among medicare enrollees. Am. J. Prev. Med. 2010, 38, 184-191. [CrossRef] [PubMed]

13. Gomez, S.L.; O’Malley, C.D.; Stroup, A.; Shema, S.J.; Satariano, W.A. Longitudinal, population-based study of racial/ethnic differences in colorectal cancer survival: Impact of neighborhood socioeconomic status, treatment and comorbidity. BMC Cancer 2007, 7, 193. [CrossRef] [PubMed]

14. Kauh, J.; Brawley, O.W.; Berger, M. Racial disparities in colorectal cancer. Curr. Probl. Cancer 2007, 31, $123-133$. [CrossRef] [PubMed]

15. Enewold, L.; Horner, M.J.; Shriver, C.D.; Zhu, K. Socioeconomic disparities in colorectal cancer mortality in the United States, 1990-2007. J. Community Health 2014, 39, 760-766. [CrossRef] [PubMed]

16. Davis, D.M.; Marcet, J.E.; Frattini, J.C.; Prather, A.D.; Mateka, J.J.L.; Nfonsam, V.N. Is it time to lower the recommended screening age for colorectal cancer? J. Am. Coll. Surg. 2011, 213, 352-361. [CrossRef] [PubMed]

17. Myers, E.A.; Feingold, D.L.; Forde, K.A.; Arnell, T.; Jang, J.H.; Whelan, R.L. Colorectal cancer in patients under 50 years of age: A retrospective analysis of two institutions' experience. World J. Gastroenterol. 2013, 19, 5651-5657. [CrossRef] [PubMed]

18. Siegel, R.L.; Jemal, A.; Ward, E.M. Increase in incidence of colorectal cancer among young men and women in the United States. Cancer Epidem. Biomar. 2009, 18, 1695-1698. [CrossRef] [PubMed]

19. Singh, S.; Singh, P.P.; Murad, M.H.; Singh, H.; Samadder, N.J. Prevalence, risk factors, and outcomes of interval colorectal cancers: A systematic review and meta-analysis. Am. J. Gastroenterol. 2014, 109, 1375-1389. [CrossRef] [PubMed]

20. National Cancer Institute. Overview of the SEER Program, 2017. Surveillance, Epidemiology, and End Results Program. Available online: https:/ / seer.cancer.gov/about/overview.html (accessed on 8 May 2017).

21. Ansa, B.; Goodman, M.; Ward, K.; Kono, S.A.; Owonikoko, T.K.; Higgins, K.; Beitler, J.J.; Grist, W.; Wadsworth, T.; El-Deiry, M.; et al. Paranasal sinus squamous cell carcinoma incidence and survival based on surveillance, epidemiology, and end results data, 1973 to 2009. Cancer 2013, 119, 2602-2610. [CrossRef] [PubMed]

22. SEER*Stat Software; version 8.3.4; Surveillance Research Program; National Cancer Institute: Bethesda, MD, USA, 2017.

23. Tiwari, R.C.; Clegg, L.X.; Zou, Z.H. Efficient interval estimation for age-adjusted cancer rates. Stat. Methods. Med. Res. 2006, 15, 547-569. [CrossRef] [PubMed] 
24. Joinpoint Regression Program; version 4.5.0.1; Statistical Methodology and Applications Branch, Surveillance Research Program; National Cancer Institute: Bethesda, MD, USA, 2017.

25. Kim, H.J.; Fay, M.P.; Feuer, E.J.; Medthune, D.N. Permutation tests for joinpoint regression with applications to cancer rates. Stat. Med. 2000, 20, 655. [CrossRef]

26. Ansa, B.E.; White, S.; Chung, Y.; Smith, S.A. Trends in HIV testing among adults in Georgia: Analysis of the 2011-2015 BRFSS data. Int. J. Environ. Res. Public Health 2016, 13. [CrossRef] [PubMed]

27. Bailey, C.E.; Hu, C.Y.; You, N.; Bednarski, B.K.; Rodriguez-Bigas, M.A.; Skibber, J.M.; Cantor, S.B.; Chang, G.J. Increasing disparities in the age-related incidences of colon and rectal cancers in the United States, 1975-2010. JAMA Surg. 2015, 150, 17-22. [CrossRef] [PubMed]

28. Siegel, R.L.; Miller, K.D.; Fedewa, S.A.; Ahnen, D.J.; Meester, R.G.S.; Barzi, A.; Jemal, A. Colorectal cancer statistics, 2017. CA Cancer J. Clin. 2017, 67, 177-193. [CrossRef] [PubMed]

29. Siegel, R.; Desantis, C.; Jemal, A. Colorectal cancer statistics, 2014. CA Cancer J. Clin. 2014, 64, $104-117$. [CrossRef] [PubMed]

30. Rim, S.H.; Seeff, L.; Ahmed, F.; King, J.B.; Coughlin, S.S. Colorectal cancer incidence in the United States, 1999-2004: An updated analysis of data from the national program of cancer registries and the surveillance, epidemiology, and end results program. Cancer 2009, 115, 1967-1976. [CrossRef] [PubMed]

31. Jackson-Thompson, J.; Ahmed, F.; German, R.R.; Lai, S.M.; Friedman, C. Descriptive epidemiology of colorectal cancer in the United States, 1998-2001. Cancer 2006, 107, 1103-1111. [CrossRef] [PubMed]

32. Williams, R.; White, P.; Nieto, J.; Vieira, D.; Francois, F.; Hamilton, F. Colorectal cancer in African Americans: An update. Clin. Transl. Gastroen. 2016, 7, 185. [CrossRef] [PubMed]

33. National Center for Health Statistics. National Health Interview Surveys 2000 and 2013; National Center for Health Statistics: Atlanta, GA, USA, 2014.

34. Siegel, R.L.; Fedewa, S.A.; Anderson, W.F.; Miller, K.D.; Ma, J.M.; Rosenberg, P.S.; Jemal, A. Colorectal cancer incidence patterns in the United States, 1974-2013. J. Natl. Cancer Inst. 2017, 109. [CrossRef] [PubMed]

35. Doubeni, C.A. The Impact of colorectal cancer screening on the US population is it time to celebrate? Cancer 2014, 120, 2810-2813. [CrossRef] [PubMed]

36. Koblinski, J.; Jandova, J.; Nfonsam, V. Disparities in incidence of early- and late-onset colorectal cancer between Hispanics and Whites: A 10-year SEER database study. Am. J. Surg. 2017, 1-5. [CrossRef] [PubMed]

37. Yantiss, R.K.; Goodarzi, M.; Zhou, X.K.; Rennert, H.; Pirog, E.C.; Banner, B.F.; Chen, Y.T. Clinical, pathologic, and molecular features of early-onset colorectal carcinoma. Am. J. Surg. Pathol. 2009, 33, 572-582. [CrossRef] [PubMed]

38. Ransohoff, D.F. Colon cancer screening in 2005: Status and challenges. Gastroenterology 2005, 128, $1685-1695$. [CrossRef] [PubMed]

39. Dobson, R. Broadcast of star's colonoscopy puts up screening by 20\%. BMJ 2002, 324, 1118. [CrossRef] [PubMed]

40. Cram, P.; Fendrick, A.M.; Inadomi, J.; Cowen, M.E.; Carpenter, D.; Vijan, S. The impact of a celebrity promotional campaign on the use of colon cancer screening-The Katie Couric effect. Arch. Intern. Med. 2003, 163, 1601-1605. [CrossRef] [PubMed]

41. Saba, N.F.; Goodman, M.; Ward, K.; Flowers, C.; Ramalingam, S.; Owonikoko, T.; Chen, A.; Grist, W.; Wadsworth, T.; Beitler, J.J.; et al. Gender and ethnic disparities in Incidence and survival of squamous cell carcinoma of the oral tongue, base of tongue, and tonsils: A surveillance, epidemiology and end results program-based analysis. Oncology 2011, 81, 12-20. [CrossRef] [PubMed]

42. Park, H.S.; Lloyd, S.; Decker, R.H.; Wilson, L.D.; Yu, J.B. Limitations and Biases of the surveillance, epidemiology, and end results database. Curr. Probl. Cancer 2012, 36, 216-224. [CrossRef] [PubMed]

(C) 2018 by the authors. Licensee MDPI, Basel, Switzerland. This article is an open access article distributed under the terms and conditions of the Creative Commons Attribution (CC BY) license (http:/ / creativecommons.org/licenses/by/4.0/). 